\title{
The energetic implications of curtailing versus storing solar- and wind-generated electricity $\dagger$
}

Cite this: Energy Environ. Sci., 2013, 6, 2804

Received 11th June 2013

Accepted 14th August 2013

DOI: 10.1039/c3ee41973h

www.rsc.org/ees

\author{
Charles J. Barnhart, ${ }^{\text {*a }}$ Michael Dale, ${ }^{a}$ Adam R. Brandt ${ }^{\mathrm{b}}$ and Sally M. Benson ${ }^{\mathrm{ab}}$
}

We present a theoretical framework to calculate how storage affects the energy return on energy investment (EROI) ratios of wind and solar resources. Our methods identify conditions under which it is more energetically favorable to store energy than it is to simply curtail electricity production. Electrochemically based storage technologies result in much smaller EROI ratios than large-scale geologically based storage technologies like compressed air energy storage (CAES) and pumped hydroelectric storage (PHS). All storage technologies paired with solar photovoltaic (PV) generation yield EROI ratios that are greater than curtailment. Due to their low energy stored on electrical energy invested $\left(\mathrm{ESOI}_{\mathrm{e}}\right.$ ) ratios, conventional battery technologies reduce the EROI ratios of wind generation below curtailment EROI ratios. To yield a greater net energy return than curtailment, battery storage technologies paired with wind generation need an $\mathrm{ESOl}_{e}>80$. We identify improvements in cycle life as the most feasible way to increase battery $\mathrm{ESOI}_{\mathrm{e}}$. Depending upon the battery's embodied energy requirement, an increase of cycle life to 10000-18000 (2-20 times present values) is required for pairing with wind (assuming liberal round-trip efficiency [90\%] and liberal depth-of-discharge [80\%] values). Reducing embodied energy costs, increasing efficiency and increasing depth of discharge will also further improve the energetic performance of batteries. While this paper focuses on only one benefit of energy storage, the value of not curtailing electricity generation during periods of excess production, similar analyses could be used to draw conclusions about other benefits as well.

\section{Broader context}

Rapid deployment of power generation technologies harnessing wind and solar resources continues to reduce the carbon intensity of the power grid. But as these technologies comprise a larger fraction of power supply, their variable nature poses challenges to power grid operation. Today, during times of power oversupply or unfavorable market conditions, power grid operators curtail these resources. Rates of curtailment are expected to increase with increased renewable electricity production. That is unless technologies are implemented that can provide grid flexibility to balance power supply with power demand. Curtailment is an obvious forfeiture of energy and it increases the lifetime cost of electricity from curtailed generators. What are less obvious are the energetic costs for technologies that provide grid flexibility. In this study we employ net energy analysis to compare the energetic cost of wind and solar generation curtailed at various rates to the energetic cost of those generators paired with storage. We find that energetic cost depends on the generation technology, the storage technology, and the rate of curtailment. In some cases it is energetically favorable to store excess electricity. In other cases, it is favorable to curtail these resources. Our goal is to stimulate the identification of new and optimum uses for excess renewable energy and research and development directions for technologies providing grid flexibility.

\section{Introduction}

The world needs affordable, accessible, sustainable and lowcarbon energy resources. ${ }^{1-3}$ Of the renewable resources, solar PV and wind turbines have the highest technical potential to satisfy this need, but these technologies generate electricity from variable, weather-dependent resources. ${ }^{4-7}$ Fig. 1 provides a

${ }^{a}$ Global Climate and Energy Project, Stanford University, Stanford, CA, USA. E-mail: charles.barnhart@stanford.edu; Fax: +1650725 9190; Tel: +16507368627

${ }^{b}$ Dept. of Energy Resources Engineering, Stanford University, Stanford, CA 94305, USA $\dagger$ Electronic supplementary information (ESI) available: EROI and ESOI data, expanded derivation of system EROI mathematical framework. See DOI: 10.1039/c3ee41973h compelling visualization of 30 days of superimposed power demand time series data (red) wind energy generation data (blue) and solar insolation data (yellow). Supply correlates poorly with demand.

To accommodate variable sources of electricity, grid-operators will deploy load-balancing techniques that increase grid flexibility. These techniques include improved forecasting of renewable generation, building excess generation capacity and transmission, natural gas firming, electrical energy storage and demand-side management. ${ }^{\mathbf{9}-12}$

In lieu of grid flexibility, variable resources are curtailed during periods of oversupply or of strong market disincentives. $^{\mathbf{1 3 , 1 4}}$ Consequently, electricity is squandered, capacity 


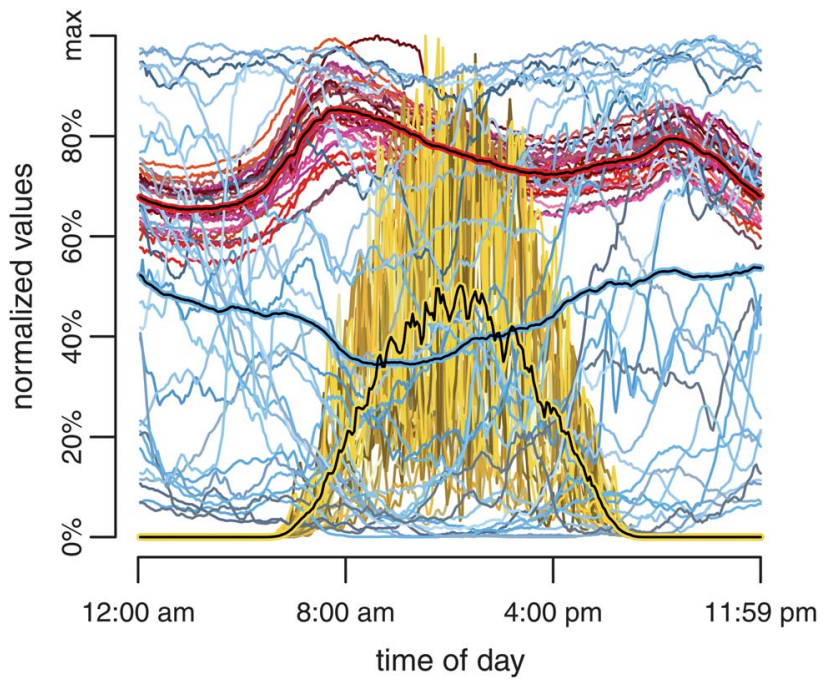

Fig. 1 Wind-power generation (blue), insolation (gold), and power demand (red) time series data provide a compelling visualization of renewable energy's intermittent correlation with demand. Thirty days of data collected in April 2010 are superimposed and normalized to their maximum values. Average values are in color-highlighted black lines. Data obtained from Bonneville Power Administration. Plot concept motivated by ref. 8 .

factors are reduced and revenue for turbine owners in certain markets is lost. In Texas, for example, $1.2-17.1 \%$ of potential wind generation was curtailed on an annual basis between 2007 and 2012, equaling a total of 13 TW h of electrical energy. ${ }^{13,29}$ Worldwide, curtailment rates are projected to increase as wind and solar comprise a larger fraction of the generation mix. ${ }^{5,13}$

Curtailing renewable resources results is an immediate and obvious forfeiture of energy. However, flexible grid technologies can also consume significant amounts of energy in their manufacture and operation. These embodied energy costs are not as immediately apparent, but they are an energy sink from a societal perspective.

Energy use, to first order, is a proxy for greenhouse gas emissions. ${ }^{15}$ Over long time scales, implementing energetically costly grid technologies may require additional energy consumption and increase emissions. This would hinder the climate change mitigation efforts that motivated increased renewable resource utilization.

In this paper, we compare the energetic costs of electrical energy storage (EES) to the energetic costs of curtailment. We ask whether or not storage provides societal net-energy gains over curtailment.

We chose to analyze EES because it currently holds academic, governmental and corporate focus, and benefits from trade organizations promoting its development and commercialization. ${ }^{16}$ Policymakers at state and national levels have drafted legislation that considers mandating the implementation of electrical energy storage. ${ }^{17}$ For example, California Assembly Bill no. 2514 requires the California Public Utility Commission to "determine appropriate targets for each loadserving entity to procure viable EES systems by October 2013, and if determined to be appropriate, to be achieved by each load-serving entity by December 2015."18
To be clear, we focus solely on comparing the energy efficiency of storing electricity versus curtailing electrical generation. EES has significant value not quantified or analyzed in this study, including electricity market economics, ${ }^{9}$ insuring reliable power supplies to critical infrastructure, ${ }^{\mathbf{1 1}}$ ancillary benefits to power grid operation, ${ }^{19}$ and application in disaster relief and war zone scenarios.

Our analysis begins with a theoretical framework for quantifying how storage affects net energy ratios. This framework accommodates any type of generation or storage technology. Using Life Cycle Assessment (LCA) data for generation and storage technologies, we calculate which storage and generation technologies result in a net energy gain over curtailment. We provide a straightforward decision metric for choosing storage or curtailment. Finally, we discuss these results and make recommendations for storage use scenarios, consider alternative options to curtailment, and identify the most effective research and development directions for improving the energetic performance of battery technologies.

\section{A theoretical framework for system-wide EROI}

The ESI $\dagger$ includes a thorough derivation of the framework for calculating the EROI of renewable generation paired with storage. In this section we present the necessary terms and equations required to calculate this paper's results.

The field of net energy analysis (NEA) is a broad system of methodologies for comparing the amount of energy delivered to society by a technology to the energy consumption over the full lifecycle of the technology. A frequently used metric in NEA is the EROI, which is the ratio of energy delivered to the lifecycle costs of energy production. ${ }^{20}$ Another metric is energy intensity, $\varepsilon$, which is the lifecycle costs of energy production per unit of energy delivered to society. ${ }^{21}$ We present our data and results in terms of EROI: the amount of electrical energy returned per unit of electrical energy invested. We present our quantitative methods in terms of energy intensity: the amount of electrical energy investment per unit of electrical energy return. EROI values are frequently reported in the literature. Energy intensities are more useful in calculating the energy performance of energy systems. EROI and $\varepsilon$ are complex terms that depend on how the inputs and outputs are defined. ${ }^{22}$ We employ these terms in a generalized manner.

We define energy intensity of a renewable energy technology as $\varepsilon_{\mathrm{r}}$ and the energy intensity of a storage technology as $\varepsilon_{\mathrm{s}}$. These are the electrical energy inputs per unit electrical energy output over the lifetime of the technology $\left[\frac{\mathrm{kWh}_{\mathrm{e}}}{\mathrm{kWh}_{\mathrm{e}}}\right]$. In this study we compute all energy calculations in terms of electrical energy. We expand $\varepsilon_{\mathrm{s}}$ by considering the energy inputs and outputs of a storage device. The input is the cradle-to-gate embodied energy, $\varepsilon_{\mathrm{e}}\left[\mathrm{kWh}_{\mathrm{e}}\right.$ embodied electrical energy per $\mathrm{kWh}_{\mathrm{e}}$ storage capacity]. The total electrical energy output from the storage device over its lifetime, per unit storage capacity, is $\lambda \eta D$, where $\lambda$ is the number of charge-discharge cycles or its cycle life [\# cycles], $\eta$ is the round-trip AC-AC efficiency, and $D$ 
is the depth of discharge [fractional] at which $\lambda$ cycles are achieved. As such,

$$
\varepsilon_{\mathrm{s}}=\frac{\varepsilon_{\mathrm{e}}}{\lambda \eta D}\left[\frac{\mathrm{kWh} \mathrm{e}_{\mathrm{e}} \text { embodied }}{\mathrm{kWh} \text { capacity }}\right] .
$$

Given the energy intensities of a generation and storage technology, $\varepsilon_{\mathrm{r}}$ and $\varepsilon_{\mathrm{s}}$, we now consider the grid-level energy intensity, $\varepsilon_{\mathrm{g}}$, of a simple energy system: a variable renewable resource rendered grid dispatchable by an EES technology. A power grid, on a time-average basis, cannot accommodate a fraction, $\phi$, of the variable resource's energy return. This fraction is curtailed or stored. Either choice increases the energy intensity of the electricity output. Curtailment increases the resource energy intensity, $\varepsilon_{\mathrm{r}}$ to $\varepsilon_{\mathrm{c}}$,

$$
\varepsilon_{\mathrm{c}}=\frac{\varepsilon_{\mathrm{r}}}{(1-\phi)}\left[\frac{\mathrm{kWh} \mathrm{h}_{\mathrm{e}} \text { embodied }}{\mathrm{kWh} \mathrm{h}_{\mathrm{e}} \text { generated }}\right] .
$$

Fig. 2 shows a diagram of the energy inputs and outputs of power grid incorporating EES at fraction $\phi$. Although the diagram shows one solar PV panel and one storage battery, it represents energy inputs and outputs generalized at societal scale. The output from storage is modulated by the storage efficiency, $\eta$, and the fractional input $\phi$. As such, the storage energy intensity, $\varepsilon_{\mathrm{s}}$, is multiplied by $\eta \phi$ to maintain a denominator of per unit electrical energy output. Summing the energy inputs, and dividing them by the output energy to the power grid, it is shown in the ESI $\uparrow$ that grid energy intensity, $\varepsilon_{\mathrm{g}}$, equals

$$
\varepsilon_{\mathrm{g}}=\frac{\varepsilon_{\mathrm{r}}+\eta \varepsilon_{\mathrm{s}} \phi}{(1-\phi+\phi \eta)}\left[\frac{\mathrm{kWh} \mathrm{Wh}_{\mathrm{e}} \text { embodied }}{\mathrm{kWh} \text { generated }}\right] .
$$

\subsection{Decreases in EROI at grid scale}

We define the EROI of a renewable resource energy acquisition technology as the inverse of $\varepsilon_{\mathrm{r}}$ : EROI $=\frac{1}{\varepsilon_{\mathrm{r}}}$. In a previous study ${ }^{23}$ we derived an analog to EROI for storage technologies: Energy Stored on Invested (ESOI). That study defined ESOI as the primary energy inputs per unit of EES capacity. $\mathrm{ESOI}_{\mathrm{e}}$ is the ratio of electrical energy stored over the lifetime of a storage device to the amount of embodied electrical energy required to build the device:

$$
\mathrm{ESOI}_{\mathrm{e}}=\frac{C \lambda \eta D}{C \varepsilon_{\mathrm{e}}}=\frac{\lambda \eta D}{\varepsilon_{\mathrm{e}}}\left[\frac{\mathrm{kWh}_{\mathrm{e}} \text { capacity }}{\mathrm{kWh}_{\mathrm{e}} \text { embodied }}\right] .
$$

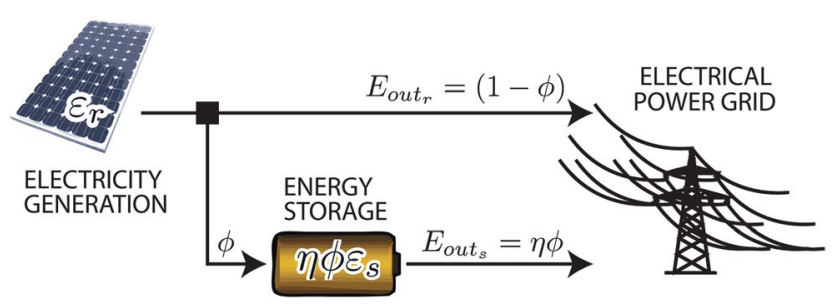

Fig. 2 A schematic of a renewable electricity-generation technology and EES system delivering electrical energy to the power grid. Terms within technologies are the energy inputs per unit output. Flow lines depict electricity outputs. where $C$ is the battery capacity $\left[\mathrm{kWh}_{\mathrm{e}}\right]$. Again, by definition $\mathrm{ESOI}_{\mathrm{e}}$ is the inverse of $\varepsilon_{\mathrm{s}}$. Curtailing a resource at some fraction $\phi$ reduces its EROI to $\mathrm{EROI}_{\text {curt }}$,

$$
\text { ESOI }_{\text {curt }}=(1-\phi) \text { EROI }\left[\frac{\mathrm{kWh}_{\mathrm{e}} \text { generated }}{\mathrm{kWh} \text { embodied }}\right] \text {. }
$$

The incorporation of storage at some fraction $\phi$ reduces the

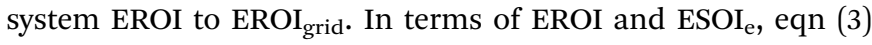
can be rearranged as

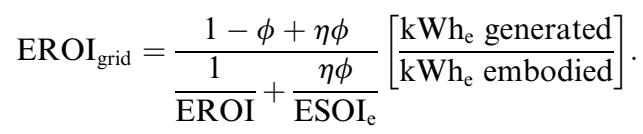

In our derivation of $\mathrm{EROI}_{\text {grid }}$ we assume that storage operates optimally and that the precise storage capacity required is built. As such, EROI $_{\text {grid }}$ is a theoretical maximum for a given generation and storage technology.

\subsection{EROI and ESOI $\mathrm{e}_{\mathrm{e}}$ data for technologies}

Table 1 lists median EROI values, median $\mathrm{ESOI}_{\mathrm{e}}$ values, and storage technology attributes used in the computation of our results. We acquired EROI data for wind turbine and PV technologies, and $\mathrm{ESOI}_{\mathrm{e}}$ data for storage technologies, by employing a $m e t a$-analysis of previous LCA studies (see ESI $\dagger$ ). Fig. 3 shows average quantile EROI values for PV solar technologies and wind farm locations. Thin film solar technologies have greater EROI values than wafer technologies (sc-Si and mc-Si). Reported EROI values for wind farms vary from less than 5 to greater than 100. Wind technologies have a much larger median EROI (86 and 89) than solar technologies (8 and 13). This is primarily due to large differences in their embodied energy. A distinct decrease in embodied energy for wafer technologies occurred in

Table 1 Data used in net energy analysis of variable resources firmed by storage

\begin{tabular}{|c|c|c|c|c|c|}
\hline \multicolumn{2}{|c|}{ Efficiency } & \multirow{2}{*}{$\begin{array}{l}\text { Cycle life } \\
\lambda^{[\mathrm{b}]}\end{array}$} & \multirow{2}{*}{$\begin{array}{l}\begin{array}{l}\text { Depth of } \\
\text { discharge }\end{array} \\
D^{[\mathrm{b}]}(\%)\end{array}$} & \multirow{2}{*}{$\begin{array}{l}\begin{array}{l}\text { Embodied } \\
\text { energy }\end{array} \\
\varepsilon_{\mathrm{e}}^{[\mathrm{c}]} \frac{\mathrm{kWh}_{\mathrm{e}}}{\mathrm{kWh}_{\mathrm{e}}}\end{array}$} & \multirow{2}{*}{$\begin{array}{l}\begin{array}{l}\text { Energy } \\
\text { ratio }\end{array} \\
\text { ESOI }_{e}{ }^{[c]} \frac{\mathrm{kWh}_{e}}{\mathrm{kWh}_{\mathrm{e}}}\end{array}$} \\
\hline Storage & $\eta^{[\mathrm{a}]}(\%)$ & & & & \\
\hline Li-ion & 90 & 6000 & 80 & 136 & 32 \\
\hline $\mathrm{NaS}$ & 75 & 4750 & 80 & 146 & 20 \\
\hline $\mathrm{PbA}$ & 90 & 700 & 80 & 96 & 5 \\
\hline VRB & 75 & 2900 & 100 & 208 & 10 \\
\hline $\mathrm{ZnBr}$ & 60 & 2750 & 80 & 151 & 9 \\
\hline CAES & 70 & 25000 & $\mathrm{n} / \mathrm{a}$ & 22 & 797 \\
\hline PHS & 85 & 25000 & $\mathrm{n} / \mathrm{a}$ & 30 & 704 \\
\hline
\end{tabular}
technologies. (Top) Attributes of storage technologies used for $\mathrm{ESOl}_{\mathrm{e}}$ ratio calculations. (Base) EROI ratios of generation resource technologies. Conventional batteries: Lithium Ion (Li-ion), Sodium Sulfar ( $\mathrm{NaS}$ ) and Lead-Acid ( $\mathrm{PbA})$. Flow batteries: Vanadium Redox (VRB) and Zinc-Bromine ( $\mathrm{ZnBr}$ ). Geologic storage: Compressed Air Energy Storage (CAES) and Pumped Hydroelectric Storage (PHS) ${ }^{a}$

Generation $\quad$ EROI $^{[\mathrm{d}]}$

$\begin{array}{lllllll}\text { Wafer PV } & - & - & - & - & - & \end{array}$

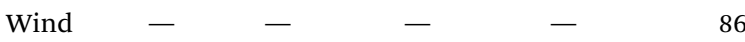

${ }^{a}$ Sources: [a] ref. 24, [b] ref. 25, [c] ref. 23, [d] ref. 26, detailed analysis in ESI. 


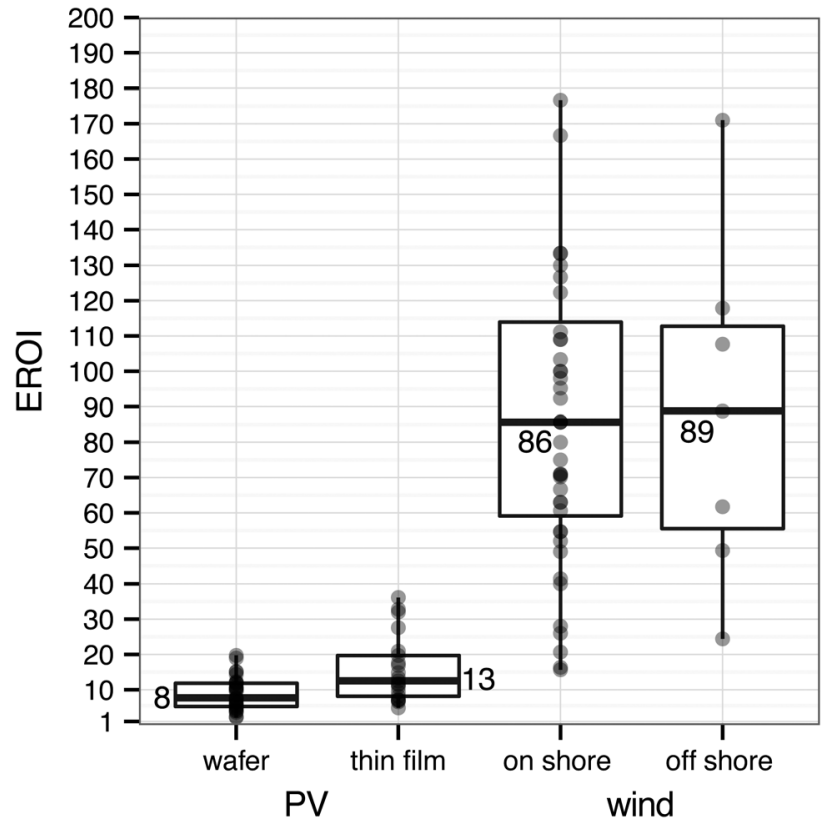

Fig. 3 EROI values for renewable technologies obtained from peer-reviewed sources are plotted by dots of $33 \%$ opacity. Boxes indicate the 25th, 50th and 75 th quantiles, and whiskers extend to lowest and highest values within in 1.5 IQR of the boxes.

the period 2005-2008, which coincides with the PV industry switching from highly purified (99.99999\% pure) electronicsgrade silicon, obtained as a waste stream from the microchip manufacturing industry, to production of its own less pure (99.999\% pure) solar-grade silicon.

We provide these EROI and $\mathrm{ESOI}_{\mathrm{e}}$ ratio data to explore storage and curtailment in the contemporary energy landscape. These ratios vary with different designs within a particular technology set and will change with technological advances. ${ }^{11,27}$ They also depend on operating practices and location. ${ }^{\mathbf{2 4}}$

As recognized in prior work, these $\mathrm{ESOI}_{\mathrm{e}}$ data demonstrate a key difference in the net energy performance of battery technologies and large-scale geological storage technologies: batteries have lower $\mathrm{ESOI}_{\mathrm{e}}$ ratios by more than two orders of magnitude. ${ }^{23}$ The values for flow and PbA batteries are particularly low. Over their entire life, these technologies only store 5 to 10 times the energy (electrical equivalents) required to build them.

EROI and $\mathrm{ESOI}_{\mathrm{e}}$ ratios are cast in units of electrical energy per electrical energy. To compare the energetic losses associated with curtailment to the energetic requirements of EES the same type of energy needs to be maintained in the theoretical framework. Two commonly used options are primary energy (e.g. higher heating value of coal, oil or gas) or some form of secondary energy (e.g. energy content of electricity). First, we cast ESOI $_{\mathrm{e}}$ in terms of electrical energy because curtailed energy is electrical, not primary energy. Second, for electrochemical storage many processes including material extraction and purification as well as battery manufacture is presently or could be electrified. ${ }^{27}$ Third, although geologic storage technologies require civil construction operations that rely on primary fuel sources, over $2 / 3$ of the capital energy expenditures could be electrified. Specifically, the energetic cost breakdown for PHS is as follows: reservoir and dam construction (104.8 GJ/MW h); tunneling (86.7); electrical equipment (134.7). ${ }^{28}$ And for CAES: cavern development (16.2); site and buildings (36.7); electrical equipment (65.9); gas infrastructure (130.5). ${ }^{28}$ Assuming reservoir construction, dam construction and cavern development require primary energy, hypothetically, about $70 \%$ of PHS and $90 \%$ of CAES deployment could be electrified.

\section{Results}

EES increases the energy intensity of renewable resources to $\varepsilon_{\mathrm{g}}$ (eqn (3)). Curtailment increases the energy intensity to $\varepsilon_{\mathrm{c}}$ (eqn (2)). By setting $\varepsilon_{\mathrm{g}}=\varepsilon_{\mathrm{c}}$ we establish a decision metric that determines when, from a net energy perspective, a variable electric resource should be stored. As demonstrated in the ESI, $\dagger$ this equality, in terms of EROI and $\mathrm{ESOI}_{\mathrm{e}}$, simplifies to

$$
\frac{\mathrm{ESOI}_{\mathrm{e}}}{\mathrm{EROI}}=1-\phi \text {. }
$$

when this equality holds, curtailment and storage yield the same grid scale EROI. Otherwise, from an energy efficiency perspective, one of two conditions exists:

$$
\frac{\mathrm{ESOI}_{\mathrm{e}}}{\mathrm{EROI}} \Rightarrow\left\{\begin{array}{l}
\text { store if }>1-\phi \\
\text { curtail if }<1-\phi
\end{array} .\right.
$$

This inequality can be rearranged to explore individual variables. For example, to determine what minimum $\mathrm{ESOI}_{\mathrm{e}}$ is required to achieve a net energy gain over curtailment the following arrangement is employed,

$$
\mathrm{ESOI}_{\mathrm{e}}>(1-\phi) \mathrm{EROI}
$$

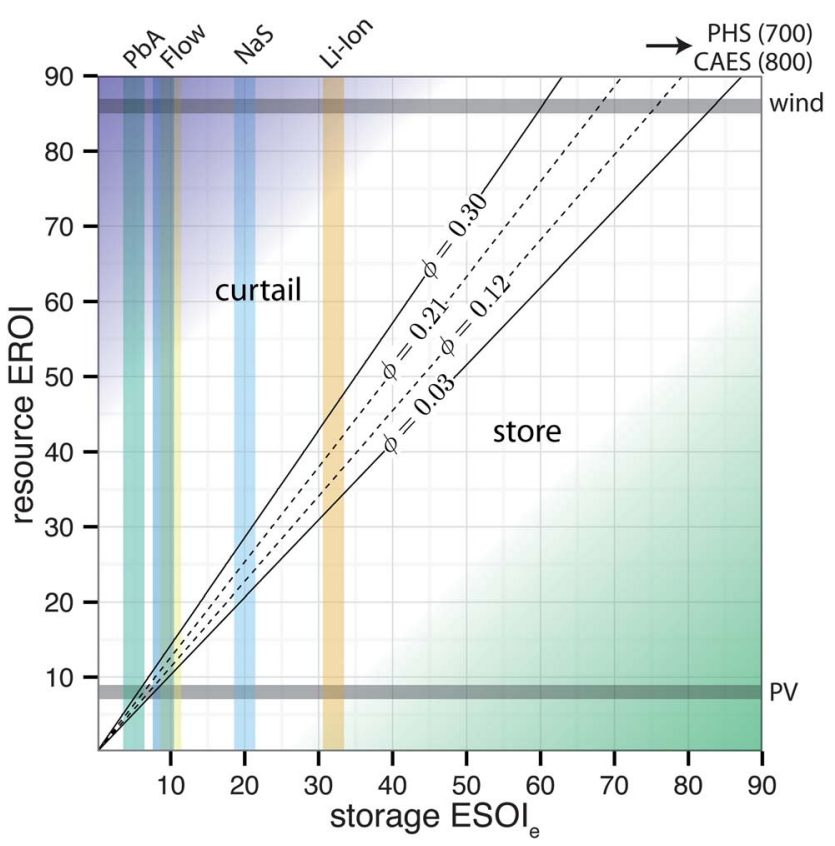

Fig. 4 At a curtailment rates or storage fractions of $\phi$, as indicated by the lines bisecting the plot, various combinations of resource EROI ( $y$-axis) and storage $\mathrm{ESOI}_{\mathrm{e}}$ ( $x$-axis) result in energy systems in which it is energetically favorable to store the resource (green region) or curtail the resource (blue region). 
Individual variables can be expanded to further explore the effects that technological attributes have on the decision to store or curtail. For example, the minimum cycle life required by electrochemical storage technologies is

$$
\lambda>(1-\phi) \operatorname{EROI} \frac{\varepsilon_{\mathrm{e}}}{\eta D} .
$$

The decision to install and operate equipment to store or curtail excess electrical energy depends on the energy resource, the storage technology, and the fraction of energy that is to be curtailed or passes through storage. Fig. 4 shows four curtailment or storage values of $\phi$ that bisect the plot into two regions.

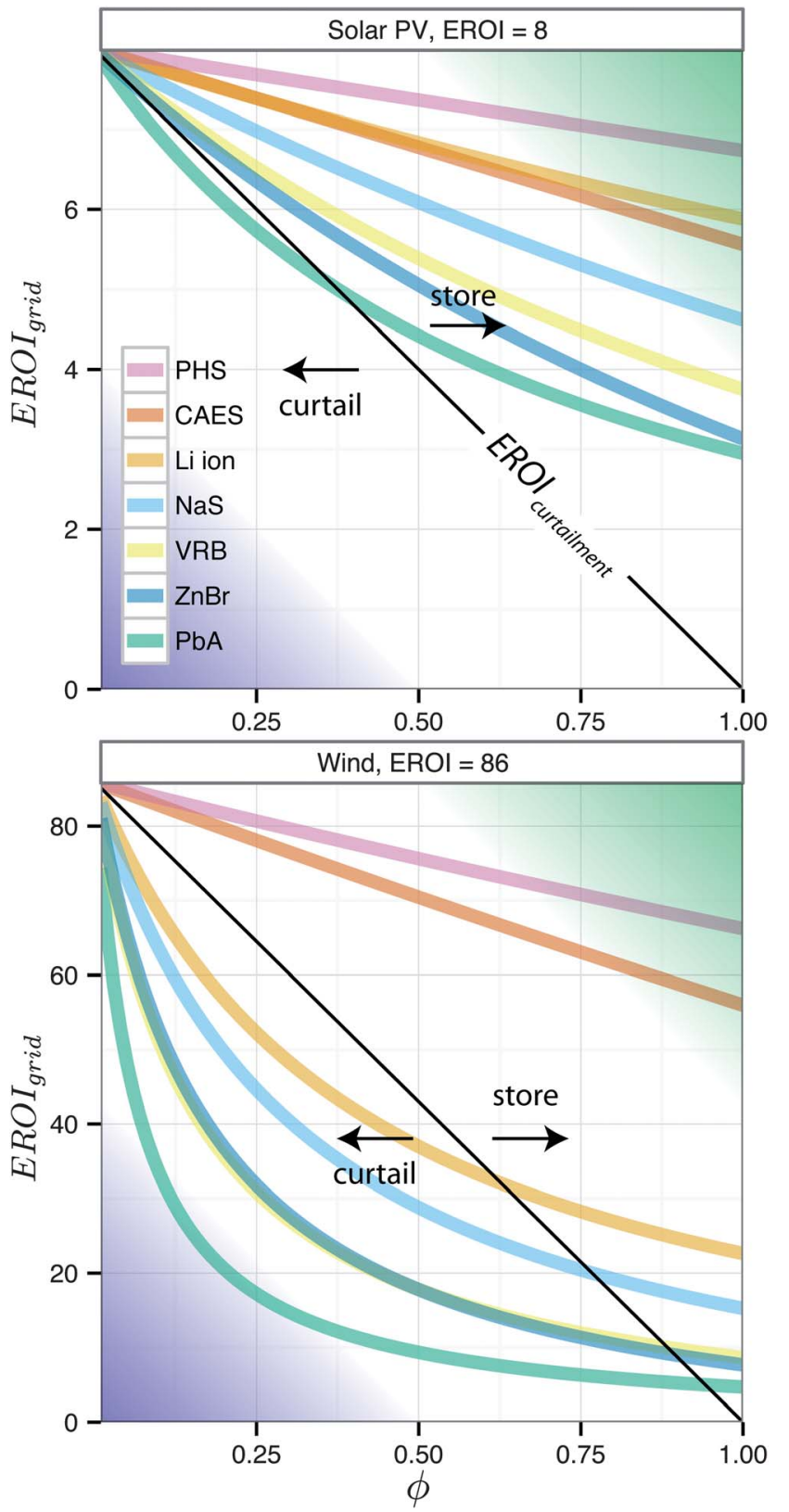

Fig. 5 EROI $_{\text {grid }}$ values as a function of storage or curtailment fraction, $\phi$, and EES technology paired with solar PV (top panel) and wind (bottom panel). Note $x$-axis is shared, but $y$-axis scale for wind is 10 greater than the $y$-axis for PV.
The blue region above and to the left of a $\phi$ line shows combinations of resource EROI ( $y$-axis) and storage $\mathrm{ESOI}_{\mathrm{e}}(x$-axis), that would reduce the grid EROI to values below reductions simply due to curtailment, i.e. $\mathrm{EROI}_{\text {grid }}<\mathrm{EROI}_{\text {curt }}$. The green region below and to the right of a $\phi$ line shows combinations of EROI and $\mathrm{ESOI}_{\mathrm{e}}$ that yield grid EROI values that are better than curtailment EROI values, $\mathrm{EROI}_{\text {grid }}>\mathrm{EROI}_{\text {curt }}$. In this region the use of storage provides a net energy gain over curtailment.

This plot tells a simple story. From a net-energy perspective, electricity generated using solar PV technologies can be stored efficiently using all plotted technologies, while wind power should be stored with more energetically favorable storage options such as PHS and CAES.

Fig. 5 shows calculated grid EROI values, EROI ${ }_{\text {grid }}$, for PV (top) and wind resources (bottom) used with storage technologies (colored lines) as a function of $\phi$. The solid black line bisecting the plots indicates the EROI value due to curtailment, spanning a range from original resource EROI to zero. The green region to the right of this line indicates combinations of EROI, $\mathrm{ESOI}_{\mathrm{e}}$ and $\phi$ in which storage yields better energy returns than curtailment, EROI $_{\text {grid }}>$ EROI $_{\text {curt }}$. To the left, in blue, $\mathrm{EROI}_{\text {grid }}<\mathrm{EROI}_{\text {curt }}$, storage implementation is more energetically costly than simply curtailing the resource.

Several interesting results emerge from Fig. 5. First, storage technologies with low $\mathrm{ESOI}_{\mathrm{e}}$ values, like $\mathrm{PbA}$ and $\mathrm{ZnBr}$, reduce the grid EROI down much more severely than technologies with high ESOI $_{e}$ values, like PHS, CAES and Li-Ion. Second, the bottom plot shows that battery technologies paired with wind yield grid EROI values far below EROI values from curtailment alone for reasonable values of $\phi$. However these grid EROI values are greater than the average PV EROI value (8).

\section{Discussion}

Ideally, storage technologies that support generation resources should not diminish energy-return ratios below curtailment energy return ratios for reasonable values of $\phi$. This means that geologic storage technologies, not contemporary battery technologies, are much more favorable for storing electricity generated from wind power.

Why do high EROI generation values require high $\mathrm{ESOI}_{\mathrm{e}}$ storage values, and why do low $\mathrm{ESOI}_{\mathrm{e}}$ values accommodate low EROI generation technologies? It is helpful to think of energy intensity as a cost. Generation with low $\varepsilon_{\mathrm{r}}$ is energetically inexpensive. Curtailing these resources does not incur as much societal scale energetic cost as using energetically expensive, i.e. low $\mathrm{ESOI}_{\mathrm{e}}$, storage technologies. Conversely, generation with high $\varepsilon_{\mathrm{r}}$ resources is energetically expensive. Curtailing these resources forfeits energy that incurred high energetic costs. These costs, in the case of PV, are greater than the cost of incorporating storage even with low $\mathrm{ESOI}_{\mathrm{e}}$ values. Attempting to salvage energetically cheap power (e.g., wind) using energetically expensive batteries is wasteful from a societal perspective. The renewable transition will be aided by choosing the most energetically efficient ways to get low carbon power.

Curtailment rates will depend on the energy and market balance of specific power grids, and on power grid flexibility. 
Two aspects play a dominant role in determining curtailment rates: the coincidence of renewable resources with power demand and the flexibility available in the power grid. As shown in Fig. 1 solar resources correlate with electricity demand more consistently than wind. This correlation is especially prevalent in regions like the southwest United States that experience high solar insolation and large afternoon power loads due to air conditioning. As renewables comprise a larger fraction of power supply, curtailment rates and power-grid conditions should be quantified and analyzed.

Grid flexibility is the second determinant for rates of curtailment. Today, in Texas, wind curtailment is due to transmission constraints. ${ }^{13}$ Increased transmission and distribution are presently reducing curtailment rates in Texas. ${ }^{29}$

The energetic performance of battery technologies can and should be improved. ESOI (eqn (4)) depends linearly on cycle life, efficiency, depth-of-discharge and embodied energy. Given the realistic values for these variables, an increase in cycle life has the greatest potential to increase $\mathrm{ESOI}_{\mathrm{e}} \cdot{ }^{23}$ Reducing the embodied energy, $\varepsilon_{\mathrm{e}}$, and improving efficiency and depth-ofdischarge will also increase ESOI ${ }_{\mathrm{e}}$. Fig. 4 employs eqn (10) and shows the number of cycles electrochemical storage technologies must achieve to outperform curtailment ( $y$-axis) when paired with wind generation $(\mathrm{EROI}=86)$ at curtailment rates or storage fractions $\phi$ ( $x$-axis).

In calculating Fig. 6 we assume the following values for the other battery attributes that define its $\mathrm{ESOI}_{\mathrm{e}}$ ratio (eqn (4) and (10)): efficiency, $\eta=90 \%$, depth of discharge, $D=80 \%$ and three embodied electrical energy-per-unit storage capacity

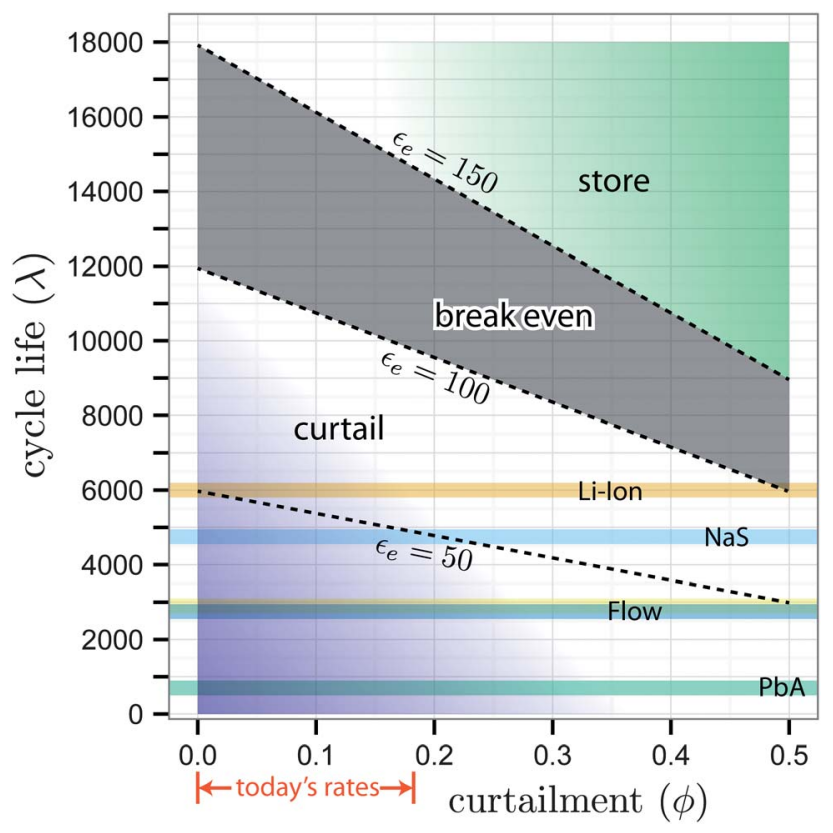

Fig. 6 A line plot of minimum cycle life values $(\lambda)$ electrochemical storage technologies must achieve to yield better EROI ratios than curtailment as a function of $\phi$ when paired with wind generation (Wind EROI is 86). Dashed lines indicate different embodied electrical energy values per unit storage capacity. Typical values for battery storage range from 100 to $150 \mathrm{kWh} / \mathrm{kWh}$. We assume other storage attributes are $\eta=0.9$ and $D=0.8$. values, $\varepsilon_{\mathrm{e}}=50,100,150 \mathrm{kWh}_{\mathrm{e}} / \mathrm{kWh}_{\mathrm{e}}$. Today's battery technologies have an $\varepsilon_{\mathrm{e}}$ between 96 and 208 (Table 1). At today's rates of curtailment (indicated by red arrows below the $x$-axis), batteries storing wind resources need to achieve a minimum cycle life of 10 000-18 000 depending on $\phi$ and $\varepsilon_{\mathrm{e}}$. This requires improvement in cycle life performance of existing technologies by a factor of 2-20 (Table 1). Recent advancements show much promise in improving cycle life, and several proposals for highcycle life grid batteries have been funded by the U.S. Department of Energy. ${ }^{30-32}$

The topic of grid energy storage currently holds the interest of policymakers and economists. It is important that the netenergy framework presented here is used appropriately and that our results do not lead to simplistic or wrong conclusions. The value of available energy depends on time, location and need. The economic value of storing energy depends on many factors including extant policies, market forces, and power grid generation availability and power demand conditions. The netenergy framework presented here is intended to aid long-term strategy and planning about the future of our energy systems. The utility lies in informing and building policy around R\&D targets, system planning, and economic incentives for energy storage systems. A conclusion that could be drawn from this work is, if society aims to increase output of (say) wind energy with the least energetic investment, it is better in many cases to just build another wind turbine, or possibly transmission lines, than to build a battery to store power that arrives at off-peak times. Conversely, the framework cannot adequately draw conclusions regarding the economic costs and benefits of storage in a given context (time, place, technology).

In closing, there are many reasons why storage provides a useful tool for increasing grid flexibility. We have focused on only one measure of the value of storage. It is equally important to consider other benefits provided by storage, including improved power quality and access to electricity in times of generation shortages, particularly in regions that lack access to an electricity grid. The value of these services needs to be weighed in comparison to other considerations, such as the net energetics we focus on here. It is also worth asking the question: are there other uses for electricity generated by wind or solar that would otherwise be stored or curtailed? For example, excess electricity could be used in applications where the need for ondemand power is low and are not strongly disadvantaged by intermittency, for example, desalinating or purifying water or driving irrigation pumps. These conditions could result in high EROI $_{\text {grid }}$ values with benefits to society that lie beyond the power-grid sector. Further research in net-energy analysis and other perspectives, including economics and environmental stewardship, should explore additional and alternative uses for energy slated for curtailment.

The energetic costs of other grid-flexibility technologies and their reduction of resource EROI should be quantified. The framework presented here can be readily tailored to technologies, including variable generation, increased transmission, and demand-side management including smart grid technology. A comparison of their energetic cost to storage and curtailment could lead to identifying energetically favorable 
combinations of grid flexibility technologies sensitive to regional power grid policy, operations and natural resources.

\section{References}

1 S. Chu and A. Majumdar, Nature, 2012, 488, 294-303.

2 J. Conti, P. Holtberg, L. E. Doman, K. A. Smith, J. O. Sullivan, K. R. Vincent, J. L. Barden, P. D. Martin, C. M. L. Mellish, D. R. Kearney and E. B. T. Murphy, International Energy Outlook 2011, DOE/EIA-0484(2011), U.S. energy information administration technical report, 2011.

3 C. Kojm, Global Trends 2030: Alternative Worlds, National Intelligence Council, 2012, p. 160.

4 D. Lew, D. Piwko, N. Miller, G. Jordan, K. Clark and L. Freeman, How Do High Levels of Wind and Solar Impact the Grid? The Western Wind and Solar Integration Study, National Renewable Energy Laboratory Technical Report, December, 2010.

5 P. Denholm and R. M. Margolis, Energy Policy, 2007, 35, 2852-2861.

6 K. Marvel, B. Kravitz and K. Caldeira, Nat. Clim. Change, 2012, 3, 118-121.

7 M. Hand, S. Baldwin, E. DeMeo, J. Reilly, T. Mai, D. Arent, G. Porro, M. Meshek and D. Sandor, NREL TP-6A20-52409, 2012.

8 D. Hawkins, Utility Wind Integration Group: Fall Technical Workshop, Sacramento, CA, 2005.

9 C. Budischak, D. Sewell, H. Thomson, L. Mach, D. E. Veron and W. Kempton, J. Power Sources, 2013, 225, 60-74.

$10 \mathrm{H}$. Chandler, Empowering Variable Renewables Options for Flexible Electricity Systems, International energy agency technical report, 2009.

11 M. Armand and J.-M. Tarascon, Nature, 2008, 451, 652-657.

12 G. Strbac, Energy Policy, 2008, 36, 4419-4426.

13 R. Wiser and M. Bolinger, 2011 Wind Technologies Market Report, U.S. Department of Energy Technical Report, August, 2012.

14 E. Lannoye, M. O. Flynn and D. Malley, IEEE Transactions on Power Systems, 2012, 27, 922-931.

15 A. Sherwani, J. Usmani and Varun, Renewable Sustainable Energy Rev., 2010, 14, 540-544.
16 B. Nicholson, Energy Storage-Maximizing Our Nation's Energy Choices, Electricity storage association technical report, 2012.

17 J. Wellinghoff, RM10-11-000 Integration of Variable Energy Resources, 2012, http://www.ferc.gov/whats-new/commmeet/2012/062112/E-3.pdf.

18 Skinner, California State Legislature, Public Utilities Code 2827.8 and 2827.1, 2010, vol. 7, pp. 1-8.

19 D. Rastler, Electricity Energy Storage Technology Options: A White Paper Primer on Applications, Costs, and Benefits, Electric power reserach institute technical report, 2010.

20 C. A. S. Hall, C. J. Cleveland and R. K. Kaufmann, Energy and resource quality: the ecology of the economic process, University Press of Colorado, 1992.

21 M. Lenzen and J. Munksgaard, Renewable Energy, 2002, 26, 339-362.

22 A. R. Brandt and M. Dale, Energies, 2011, 4, 1211-1245.

23 C. J. Barnhart and S. Benson, Energy Environ. Sci., 2013, 6, 1083-1092.

24 T. Reddy and D. Linden, Linden's Handbook of Batteries, McGraw-Hill Prof Med/Tech, 4th edn, 2010, p. 1200.

25 C. Rydh and B. Sandén, Energy Convers. Manage., 2005, 46, 1957-1979.

26 M. Dale and S. M. Benson, Environ. Sci. Technol., 2013, 47(7), 3482-3489.

27 J. L. Sullivan and L. Gaines, A Review of Battery LifeCycleAnalysis: State of Knowledge and Critical Needs ANL/ ESD/10-7, Argonne national laboratory technical report, 2010.

28 P. Denholm and Kulcinski, Energy Convers. Manage., 2004, 45, 2153-2172.

29 R. Wiser and M. Bolinger, 2012 Wind Technologies Marker Report - DOE/GO-102013-3948, LBNL Technical Report August, 2013.

30 M. Pasta, C. D. Wessells, R. a. Huggins and Y. Cui, Nat. Commun., 2012, 3, 1149.

31 Z. Zhan, D. Han, T. Wu, X. Ye, S. Wang, T. Wen, S. Cho and S. a. Barnett, RSC Adv., 2012, 2, 4075.

32 U.S. Department of Energy ARPA-E, ARPA-E PROJECT SELECTIONS OPEN FOA Advanced Fuels Last Updated: November 28, 2012, http://arpa-e.energy.gov/sites/default/ files/documents/files/OPEN2012ProjectDescriptions.pdf. 